\title{
Missing or incomplete dental records: prevalence at Medunsa Oral Health Centre
}

SADJ August 2019, Vol. 74 No. 7 p383 - p388

SR Mthethwa', SA Matjila²

\section{ABSTRACT}

\section{Introduction}

Incomplete or missing records compromise the validity and reliability of investigations.

\section{Aims and objectives}

This study describes the extent of the problem of missing or incomplete records at Medunsa Oral Health Centre. Dental records of repeat patients who consulted during July 2017 were assessed for completeness. The proportion missing was determined.

\section{Design}

This was a retrospective, descriptive cross-sectional study in which existing dental records were reviewed.

\section{Methods}

A systematic random sample of 110 dental records of repeat patients who consulted at Medunsa Oral Health Centre during July 2017 was traced in records rooms.

Eleven routine data items were selected for evaluation of completeness. A yes or no checkbox was ticked in Microsoft Excel software to indicate whether or not the information was entered in the record.

\section{Results}

A response rate of $79.1 \%$ was obtained. The first visit of $87.3 \%$ of patients occurred in the past six years. A scant $3.6 \%$ of the records were fully completed; half were less than $80 \%$ completed. Records of a third of patients who had visited the hospital for the first time in 2011 could not be found.

\section{Conclusions}

The standard of record-keeping in this random sample falls far short of the HPCSA standard.

\section{Author affiliations:}

1. Sibusiso R Mthethwa: $B D S, M P H, P h D$., Sefako Makgatho Health Sciences University, Pretoria, South Africa. ORCID Number: 0000-0003-0420-808x

2. Sello A Matjila: BDT, BDS, Dip Odont, MBL., Sefako Makgatho Health Sciences University, Pretoria, South Africa. ORCID Number: 0000-0001-5446-6904

Corresponding author: Sibusiso R Mthethwa

Medunsa Campus, PO Box D24, Sefako Makgatho Health Sciences

University 0204

Tel: +27 (0)125215888

Email: rocky.mthethwa@smu.ac.za

Author contributions:

1. Sibusiso R Mthethwa: Conception; design; acquisition of data analysis and interpretation of data; drafting the article - 90\%

2. Sello A Matjila: Acquisition of data; revising the article critically for important intellectual content - $10 \%$

\author{
ACRONYMS \\ ICD-10: International Classification of Diseases and Related \\ Health Problems ( $10^{\text {th }}$ revision) \\ MOHC: Medunsa Oral Health Centre
}

\section{INTRODUCTION \& BACKGROUND}

Health records may be used for research purposes. ${ }^{1-3}$ However, incomplete or missing records are an obstacle to record-based research. They compromise the validity and reliability of investigations. ${ }^{1}$ The Health Professions Council of South Africa (HPCSA) recommends that health records should be retained for at least six years. ${ }^{2}$ Two recent independent studies, in the fields of physiotherapy and dentistry respectively, reported highly variable incidences of missing records - suggesting that this guideline is not routinely observed. Wegner and Rhoda (2013) found that only 39\% of the records of patients who received lower limb amputation within a two year research period at four rural district hospitals could be located. ${ }^{4}$ Mthethwa and Chabikuli (2016) reported a non-response rate approximating one in ten in a study investigating the efficiency of the referral system at Medunsa Oral Health Centre (MOHC), a dental school and referral hospital in Garankuwa on the outskirts of Pretoria. 5

The purpose of keeping records is to ensure the continuity of care and to share relevant information with other members of the multidisciplinary team. ${ }^{2}$ Therefore, records must be sufficiently comprehensible so that another practitioner relying on the record can assume ongoing care of the patient. ${ }^{6}$ Incomplete records, however, sadly are common. A survey of anaesthetic records at a hospital in Cape Town found that less than a third (29.9\%) of a selected sample of 284 records were legible and complete. $^{1}$ These findings are consistent with those of Mthethwa and Matjila (2018) who found that a little more than five percent $(5.4 \%)$ of records of patients who had been prescribed antibiotics at $\mathrm{MOHC}$ did not record a diagnosis. ${ }^{7}$

An association between the quality of records and quality of care at health-care facilities in the Netherlands has been reported. ${ }^{3}$ It was found that the poor quality (completeness, readability and adequacy) of the available patient information was associated with higher rates of adverse events). ${ }^{3}$

Inadequate care occurring as a consequence of poor quality records could result in patient dissatisfaction with the health services delivered. The patient could 
thus potentially file a malpractice complaint against a health-care practitioner. In such cases, medical records also serve as a medico-legal document. ${ }^{2}$

Treating patients without complete information poses an important challenge to patient safety, increasing the likelihood of medical errors, adverse events, duplication of laboratory tests and procedures, and increased health care costs. ${ }^{8-10}$

A review of the medical records of over 14,000 admissions to 28 hospitals in New South Wales and South Australia revealed that $1.8 \%$ of the 2353 adverse events reported were due to 'acting on insufficient information' with $26.4 \%$ of these leading to permanent disability. ${ }^{11}$

The incidental findings of incomplete or missing dental records in studies carried out at $\mathrm{MOHC}$ warranted an examination of the extent of the problem. Dental records consist of a variety of material generated and stored in handwritten and electronic format which includes: Notes made by clinicians and staff; completed written medical history; consent documents; copies of correspondence about and with the patient; radiographs, tracings, and measurements; digital records including CAD/CAM records; diagnostic images, reports and study casts; special test findings; photographs; records of financial transactions; and appointment books. ${ }^{6}$

\section{OBJECTIVES OF THE STUDY}

To estimate the proportion of missing dental records of repeat patients who consulted at the diagnostic unit during July 2017.

To evaluate the completeness of dental records of repeat patients who consulted at the diagnostic unit during July 2017.

\section{MATERIALS AND METHODS}

\section{Study design}

This was a retrospective, cross-sectional descriptive study in which existing dental records were reviewed.

\section{Target population}

The sampling frame consisted of the dental records of 543 repeat patients, not on the hospital appointment system, who consulted at the diagnostic unit of $\mathrm{MOHC}$ during the month of July 2017 .

\section{Study sample}

The ideal sample size was estimated at 110 dental records in Epi Info Version 3.5.4 software at the confidence interval of $95 \%$ and absolute precision of $5 \%$ assuming a non-response rate of $10 \%$

\section{Sampling method}

A systematic random sample was selected i.e. a list of the entire patient population using patient names was prepared in Excel; the sample size of 110 was divided into the total population (543) to calculate the $K^{\text {th }}$ number, the sampling interval. The $\mathrm{K}^{\text {th }}$ number was 5 . A random starting point was therefore between 1 and 5 , and 5 was selected. We started with the fifth person and picked every fifth person on the list. ${ }^{13}$

\section{DATA COLLECTION}

Permission to enter the records rooms was obtained from the Records Officer following receipt of ethical clearance. Between September 2017 and March 2018 and under the guidance of record clerks, paper-based records of repeat patients who had consulted at the diagnostic unit of $\mathrm{MOHC}$ during the month of July 2017 were traced, using folder numbers.

Retrieved records were assessed for completeness. Eleven routine data items were selected for evaluation of completeness. These comprised: chief complaint and history; dental history; completed health questionnaire; extra-oral findings including diagnosis/ differential diagnosis; intra-oral findings including diagnosis/differential diagnosis; referral priorities for specific problems; signed consent form; treatment; tariff code; ICD code, and student/doctors name and signature. Data were captured in Microsoft Excel software - a yes or no checkbox was ticked to indicate whether or not the information had been entered in the record.

\section{Definition of variables and terms}

Diagnostic unit refers to a screening and referral clinic. At $\mathrm{MOHC}$ new and repeat self-referred and referred patients, who are not on the hospital appointment system, routinely move between the diagnostic unit to be examined by experienced dentists and clinical units where dental students under faculty supervision provide treatment or treatment appointments are scheduled.

Repeat patients are self-referred and referred patients, not on the hospital appointment system, who, according to their folder numbers, were not visiting the clinic for the first time.

An incomplete record is any record missing any of the required content.

A missing record was defined as any record that was not able to be found because it was not in its expected place (records room).

Year of first visit refers to the year the patient first visited the hospital according to the folder number.

\section{Ethical considerations}

Ethical approval for the study was granted by the Ethics Committee of the Sefako Makgatho Health Sciences University. (Clearance certificate number) Permission to conduct the study was granted by the Chief Executive Officer (CEO) of $\mathrm{MOHC}$. 


\section{STATISTICAL ANALYSIS}

Data were captured, coded and cleaned in Microsoft Excel software and then transferred to Statistical Analysis Software (SAS) software for analysis. Means, frequencies and proportions (percentages) were calculated.

\section{RESULTS}

Data of a systematic random sample of 110 records were analysed.

A response rate of $79.1 \%$ was obtained i.e. one out of five records was lost to follow up. Records of a third (3/9) of patients who had visited the hospital for the first time in 2011 could not be found.

Furthermore, records of $22 \%(10 / 45)$ of patients who had visited the hospital for the first time within the last two years could not be found. The first visit of $87.3 \%$ (96/110) of patients had occurred in the past six years. A little more than a quarter (28/110) had made their first visit in the previous year.

A scant proportion (3.6\%) of the records was fully completed. Half of the records were less than $80 \%$ completed.

Details of past medical and dental history were entered in more than $70 \%$ of the records.

On the one hand, data on intra-oral findings were entered in a little more than sixty percent $(62.7 \%)$ of the records. On the other hand, data on extra-oral findings were not entered in an identical proportion of records $(62.7 \%)$.
Data on referral priorities, treatment, signature by either the student or dental practitioner, and tariff code were entered in $70 \%$ of the records. A consent form was not signed in a little more than sixty percent (60.9\%) of the records. Data on ICD codes were not entered in a little less than sixty percent (58.2\%) of the records.

\section{DISCUSSION}

This study set out to describe the extent of the problem of incomplete or missing dental records at $\mathrm{MOHC}$.

\section{Year of first visit}

The results of this study indicate that the first visit of $87.3 \%$ of patients had occurred in the past six years. This finding is significant in that it allowed the study to investigate whether the HPCSA's recommendation that health records should be retained for at least six years was observed at $\mathrm{MOHC}$. Data on the number of subsequent visits and the nature of treatments was not collected as it was deemed irrelevant for this purpose.

Another important finding was that a little more than a quarter (28/110) of patients had made their first visit in the past year. This finding is significant in that a repeat visit, if not for emergency care, indicates that the appointment system at $\mathrm{MOHC}$ is not effective.

In their description of the referral system which operates between the diagnostic unit and clinical units, Mthethwa and Chabikuli (2016) assert that patients with less urgent problems are referred for general dental care and/or for initial assessment in the relevant specialty clinics. They are placed on a waiting list for care and are informed when a booking becomes available. ${ }^{5}$

\begin{tabular}{|c|c|c|c|c|c|c|c|c|c|}
\hline \multirow[t]{2}{*}{ Records } & \multicolumn{8}{|c|}{ Year of first visit } & \multirow[t]{2}{*}{ Total } \\
\hline & $\begin{array}{l}2009 \\
\text { n (\%) }\end{array}$ & $\begin{array}{l}2010 \\
\text { n (\%) }\end{array}$ & $\begin{array}{l}2011 \\
\text { n (\%) }\end{array}$ & $\begin{array}{l}2012 \\
n(\%)\end{array}$ & $\begin{array}{l}2013 \\
\text { n (\%) }\end{array}$ & $\begin{array}{l}2014 \\
\text { n (\%) }\end{array}$ & $\begin{array}{l}2015 \\
\text { n (\%) }\end{array}$ & $\begin{array}{l}2016 \\
\text { n (\%) }\end{array}$ & \\
\hline Missing & $0(0)$ & 3 (23.1) & 3 (33.3) & $0 \quad(0)$ & $2(15.4)$ & $5 \quad(29.4)$ & $5 \quad(29.4)$ & $5 \quad(17.9)$ & $23 \quad(20.9)$ \\
\hline Found & $1(100)$ & $10(76.9)$ & $6(66.7)$ & $12(100)$ & $11(84.6)$ & $12(70.6)$ & $12(70.6)$ & $23(82.1)$ & $87 \quad(79.1)$ \\
\hline Total & $1(100)$ & $13(100)$ & 9 (100) & $12(100)$ & $13(100)$ & $17(100)$ & 17 (100) & $28(100)$ & $110(100)$ \\
\hline
\end{tabular}

\begin{tabular}{|c|c|}
\hline Proportion of entered data items & $n(\%)$ \\
\hline $21 \% \leq 40 \%$ & $2(1.8)$ \\
\hline $41 \leq 60 \%$ & $6(5.4)$ \\
\hline $61 \leq 80$ & $47(42.8)$ \\
\hline $81 \leq 92$ & $28(25.4)$ \\
\hline $100 \%$ & $4 \quad(3.6)$ \\
\hline TOTAL & $87(79.1)$ \\
\hline
\end{tabular}

\begin{tabular}{l|c|c|}
\hline \multicolumn{3}{l}{ Table 3. Completeness of medical and dental history data. } \\
\hline Items & Recorded $\mathbf{n}(\%)$ & Unrecorded $\mathbf{n}(\%)$ \\
\hline Chief complaint and history & $87(79.1)$ & 0 \\
\hline Dental history & $81(73.6)$ & $6(5.5)$ \\
\hline $\begin{array}{l}\text { Completed health } \\
\text { questionnaire }\end{array}$ & $82(74.5)$ & $5(4.5)$ \\
\hline *23 (20.9\%) records missing & & \\
\hline
\end{tabular}

\begin{tabular}{l|c|c|}
\hline \multicolumn{2}{|l|}{$\begin{array}{l}\text { Table 4. Completeness of clinical examination data. } \\
\text { Items }\end{array}$} & $\begin{array}{l}\text { Recorded } \mathbf{n}(\%) \\
\text { Itemrecorded } \mathbf{n}(\%)\end{array}$ \\
\hline $\begin{array}{l}\text { Extra-oral findings including } \\
\text { diagnosis/differential diagnosis }\end{array}$ & $18(16.4)$ & $69(62.7)$ \\
\hline $\begin{array}{l}\text { Intra-oral findings including } \\
\text { diagnosis/differential diagnosis }\end{array}$ & $69(62.7)$ & $18(16.4)$ \\
\hline *23 (20.9\%) records missing & & \\
\hline
\end{tabular}

\begin{tabular}{|c|c|c|}
\hline Items & Recorded n (\%) & Unrecorded n (\%) \\
\hline $\begin{array}{l}\text { Referral priorities for } \\
\text { specific problems }\end{array}$ & $85(77.3)$ & $2(1.8)$ \\
\hline Treatment & $82(74.5)$ & $3(2.7)$ \\
\hline Tariff code & $77(70.0)$ & $10(9.1)$ \\
\hline ICD code & $23(20.9)$ & $64(58.2)$ \\
\hline Signed consent form & $20(18.2)$ & $67(60.9)$ \\
\hline $\begin{array}{l}\text { Student/doctors name and } \\
\text { signature }\end{array}$ & $81(73.6)$ & $6(5.5)$ \\
\hline *23 $(20.9 \%)$ records missinc & & \\
\hline
\end{tabular}




\section{Accessibility of records}

The current study obtained a response rate which was a little less than eighty percent (79.1\%). This response rate was relatively lower $(91.3 \%$ vs $79.1 \%)$ than that obtained by Mthethwa and Chabikuli (2016) in a previous research study. ${ }^{5}$

It is difficult to explain this result, but it might be related to a recently introduced practice of allowing final year students to file in a special room the records of their patients who are on the appointment system.

These records are meant to be returned to the main records room by the end of the current week. However, this does not always happen as is demonstrated by the fact that some study records were found in the special records room.

This suggests that the coordination of record keeping between the main and special record rooms is not efficient. There are, however, other possible explanations. A further study with more focus on the reasons for the decreased response rate is recommended.

In this study, records of a third (3/9) of patients who had visited the hospital for the first time six years ago could not be found. This result has not previously been described. It is disappointing and suggests that the HPCSA guideline that health records should be retained for at least six years is not routinely complied with at $\mathrm{MOHC}$. However, with a small sample size, caution must be applied in interpreting these data.

The current study found that records of $22 \%(10 / 45)$ of patients who visited the hospital for the first time within the last two years could not be found. It is perhaps encouraging to compare this figure with that reported by Wegner and Rhoda (2013) who found that only 39\% of requested records of patients who had received lower limb amputation within the two year research period, could be located. ${ }^{4}$

\section{Levels of completeness of records}

The results of this study show that a very small percentage $(3.6 \%)$ of records was fully completed and that half were less than $80 \%$ completed.

The present findings seem to be consistent with other research which found that $21 \%$ of dental practitioners in Chennai (India) did not maintain any form of dental record and that only $12 \%$ maintained complete dental records. ${ }^{12}$ The findings are out of keeping with the HPCSA's exhortation to health professionals to keep complete records.

The significance of accurate and complete records cannot be overemphasized. Legible, accurate and complete records are essential, among other things: in furthering the diagnosis or ongoing clinical management of the patients ${ }^{2}$; in forensic identification ${ }^{13}$ and in any malpractice suit. ${ }^{14}$ The extent of the problem of incomplete dental records is an important issue for future research.

\section{Completeness of medical and dental history data}

The current study found that details of past medical and dental history were not entered in records of between 20 and 25 percent of patients. This rather disappointing finding has important implications for patient safety and quality of care. It is generally accepted that past medical history is a powerful diagnostic technology ${ }^{15}$ and an essential component of risk assessment for the likelihood of a patient experiencing a medical emergency. ${ }^{16}$ A patient's medical history increases the dentist's awareness of diseases and medication which might interfere with the patient's dental treatment. ${ }^{17}$

It is also commonly accepted that a thorough past dental history can aid significantly in treatment planning, case selection, and ultimately malpractice defense. ${ }^{18}$ It enables an evaluation of the patient's attitude toward dental care and his/her previous experience of dental treatment and its nature. ${ }^{16}$ The previous use of local anaesthetic agents and any associated problems can be checked and adverse events, such as post-extraction haemorrhage, may be highlighted. ${ }^{16}$

\section{Completeness of clinical examination data}

The results of this study show a disparity in the recording of intraoral and extraoral examinations. Intraoral findings were entered in $62.7 \%$ of patient records in contrast to $16.4 \%$ for extraoral findings. The findings of the current study are consistent with other research which found that extraoral examination is offered less frequently to patients in the dental setting. ${ }^{19}$ This is unfortunate since extraoral and intraoral soft tissue examination is an essential part of any new patient examination. ${ }^{16}$ A complete examination covers the following three areas: a. the general examination - briefly assesses the patient's general appearance; b. the extraoral head and neck soft tissue examination - focuses on the head and neck, c. the intraoral soft tissue examination - determines whether the soft tissue is within normal limits. ${ }^{20}$

\section{Completeness of treatment plan data}

The current study found that referrals to clinical units were not entered in the records of one out five $(22.7 \%)$ patients. Considering the functioning of $\mathrm{MOHC}$ 's internal referral system, this result was unexpected. At $\mathrm{MOHC}$ all patients not on the hospital referral system consult at the diagnostic unit and are referred to clinical units where dental students under faculty supervision provide treatment or treatment appointments are scheduled.

A possible explanation for this result might be that the original folder could not be found and so a new one was created, using the old folder number. Another possible explanation is that the dentist the patient consulted deemed it unnecessary to make a referral after reassuring the patient/parent - a child that is brought to the hospital due to parental concern about delayed eruption is a good case in point. Further work is required to establish why referrals were not entered in patients' records. 
A most relevant finding was that details about the clinical procedures performed were not entered in the records of one out of four (25.5\%) patients. This result is contrary to expectations. The HPCSA asserts that it is compulsory to maintain this information for each patient consulted. It is difficult to explain this result.

Another important finding was that tariff codes were not entered in 30 percent of patients' records. The tariff reflects the opinion of the Medical and Dental Board on the amounts that should be charged for the respective services in instances where a practitioner and a patient have not agreed to an alternative fee. ${ }^{21}$ The reason for the lack of recording of tariff codes is not clear but it may have something to do with the fact that some categories of patients are exempted from paying user fees.

At $\mathrm{MOHC}$ patients are classified based on individual or household annual incomes for the determination of fees. Patients qualifying for full subsidisation are classified HO. Patients qualifying for partial subsidisation are classified $\mathrm{H} 1, \mathrm{H} 2$ \& $\mathrm{H}_{3}{ }^{22}$ User fees have been shown to deter utilisation of public sector health services, even when needed, particularly among the poorest in African countries. ${ }^{23}$ Notwithstanding patient classification, the failure to record tariff codes has a negative impact on correct patient billing and revenue collection.

The results of this study indicate that one out four (26.4\%) dental records was not signed by either the student or dental practitioner who attended to the patients. This unexpected finding contravenes Rule 15 of the HPCSA's ethical rules which states that:

"Any student, intern or practitioner who, in the execution of his or her professional duties, signs official documents relating to patient care, such as prescriptions, certificates (excluding death certificates) patient records, hospital or other reports, shall do so by signing such document next to his or her initials and surname in block letters."

The current study found that ICD codes and patient signature on a consent form were not entered in $58.2 \%$ and $60.9 \%$ of the records respectively. ICD-10 stands for International Classification of Diseases and Related Health Problems ( $10^{\text {th }}$ revision). It is a coding system developed by the World Health Organisation (WHO) that translates the written description of medical and health information into standard codes.

These codes are used to inform medical schemes about the conditions for which their members received treatment so that claims can be settled correctly. ${ }^{24}$ It is in the best interest of $\mathrm{MOHC}$ that accurate ICD codes are entered in the patients' records since medical schemes have the right to reject claims on the basis of inaccurate ICD-10 coding. ${ }^{25}$

It is widely recognized that obtaining a patient's consent to treatment is not just a matter of asking for a signature on a consent form - it is a communication process. For consent to be valid, it must be obtained from a competent, informed person, free from undue duress. The person giving consent must be given all relevant information, including the material risks and consequences of each option, including no treatment. ${ }^{26}$ In most routine dental examinations and treatments the patient's consent is obtained verbally. 6,27 However, the treatment must still be witnessed and documented in the patient's records. ${ }^{27}$

\section{Limitations of the study}

A potential threat to the internal validity of this study was the loss to follow up of $20.9 \%$ (23/110) of the study sample.

\section{CONCLUSION}

The standard of record-keeping in this random sample falls far short of the HPCSA standard.

\section{References}

1. Raff M, James MFM. An audit of anaesthetic record keeping. SAJAA. 2003; 9(3): 79.

2. HPCSA guidelines for good practice in the health care professions: Guidelines on the keeping of patient records. Booklet 14, 2008. Available: http://www.hpcsa.co.za/ downloads/conduct_ethics/rules/generic_ethical_rules/ booklet_14_keeping_of_patience_records.pdf [Accessed 14 January 2019].

3. Zegers M, de Bruijne MC, Spreeuwenberg P, Wagner C, Groenewegen PP, van der Wal G. Quality of patient record keeping: an indicator of the quality of care? BMJ Quality \& Safety. 2011; 20: 314-8

4. Wegner L, Rhoda A. Missing medical records: an obstacle to archival survey-research in a rural community. South African Journal of Physiotherapy 2013; 69(2): 15-9.

5. Mthethwa SR, Chabikuli NJ. The efficiency of the referral system at Medunsa Oral Health Centre. SADJ 2016; 71(10): 448-53

6. Australian Dental Association (ADA). Policy Statement 5.17 - Dental Records, 2018. Available: https://www.ada. org.au/Dental-Professionals/Policies/Third-Parties/5-17Dental-Records/ADAPolicies_5-17_DentalRecords_V1 [Accessed 14 January 2019].

7. Mthethwa SR, Matjila SA. Antibiotic prescribing practices of dentists at Medunsa Oral Health Centre. SADJ. 2018; 73 (8): 518-24.

8. Leape LL, Bates DW, Cullen DJ, et al. ADE Prevention Study Group. Systems analysis of adverse drug events. JAMA. 1995; 274(1): $35-43$.

9. Feied CF, Handler JA, Smith MS, et al. Clinical information systems: instant ubiquitous clinical data for error reduction and improved clinical outcomes. Acad Emerg Med. 2004; 11(11): 1162-9.

10. Brailer DJ. Interoperability: the key to the future health care system. Health Affairs (Millwood) 2005; Jan-Jun; Suppl Web Exclusives:W5-19-W5-21. Available: https:// www.healthaffairs.org/doi/full/10.1377/hlthaff.w5.19?url_ ver=Z39.88-2003\&rfr_id=ori\%3Arid\%3Acrossref.org\&rfr_dat $=$ cr_pub\%3Dpubmed\& [Accessed 14 January 2019].

11. Wilson RM, Runciman WB, Gibberd RW, Harrison BT, Newby L, Hamilton JD. The quality in Australian Health Care Study. Med J Aust. 1995; 163(9): 458-71.

12. Preethi S, Einstein A, Sivapathasundharam B. Awareness of forensic odontology among dental practitioners in Chennai: A knowledge, attitude, practice study. J Forensic Dent Sci. 2011; 3(2): 63-6.

13. Charangowda BK. Dental records: An overview. J Forensic Dent Sci. 2010; 2(1): 5-10. 
14. Devadiga A. What's the deal with dental records for practicing dentists? Importance in general and forensic dentistry. J Forensic Dent Sci. 2014; 6(1): 9-15.

15. Summerton $N$. The medical history as a diagnostic technology. Br J Gen Pract. 2008; 58(549): 273-6.

16. 16. Greenwood M. Essentials of medical history-taking in dental patients. Dent Update 2015; 42: 308-15.

17. van Diermen DE, Brand HS, Vissink A. The importance of adequate medical history taking in dentistry. Ned Tijdschr Tandheelkd. 2006; 113(5): 172-5. Available at: https:// www.ncbi.nlm.nih.gov/pubmed/16729560 [Accessed 14 January 2019].

18. Little JP, Pollack BR. Esthetics and Dental Jurisprudence In: Aschheim KW, ed. Esthetic Dentistry: A Clinical Approach to Techniques and Materials. Elsevier Inc. 2015: 520-31

19. Johns SG. The extraoral examination from the perspective of the patient. J Dent Hyg. 2001; 75(4):282-9.

20. Burgess K. Extraoral and intraoral soft tissue examination. Available at: https://iits.dentistry.utoronto.ca/extraoral-andintraoral-soft-tissue-examination. Accessed [11 February 2019].

21. HPCSA. Guideline tariffs for dental practitioners. Available at: http://www.hpcsa.co.za/downloads/service_fees-tariff/ guideline_tariffs_dental_practitioners_12_aug_2012.xlsx Accessed [14 January 2019].

22. Department of Health. Explanation of the Current Policy Regarding the Classification of Patients for the Determination ofFees. Availableat: www.health.gov.za/index.php/ uniform-patient.../108-u2012?...classification...[Accessed 14 January 2019].

23. Araoyinbo, I. D. and Ataguba, J. E. User fees in Africa: from theory and evidence, what next? An essay submitted to the African Health Economics and Policy Association (AFHEA). 2008, Available at: http://www.who.int/alliancehpsr / Araoyinbo_Ataguba_UserFees Africa.pdf. [Accessed 11 February 2019].

24. Council for Medical Schemes. The importance of ICD-10 codes. Availableat: http://www.medicalschemes.com/medical_schemes_pmb/icd-10_codes.htm. Accessed [11 February 2019].

25. Khan M. Coding guidelines for dentists. SADJ. 2014; 69(6): 246-8.

26. Medical Protection Society. Consent to Medical Treatment in South Africa An MPS Guide. Available https://www. medicalprotection.org/docs/default-source/pdfs/bookletpdfs/sa-booklets/consent-to-medical-treatment-in-southafrica---an-mps-guide.pdf?sfvrsn=47b64eac_4. Accessed [14 January 2019].

27. Sykes LM, Evans WG Harryparsad A. Dental images in: Communication Ethics Law and Research in Dentistry. A South African Dental Association Publication, 2017: 98-101. 